\title{
AACVD synthesis of catalytic gold nanoparticle-modified cerium(IV) oxide thin films
}

\author{
Meghan Evans ${ }^{1}$, Francesco Di Maggio', Chris Blackman ${ }^{*}, 1$, Gopinathan Sankar ${ }^{1}$ \\ ${ }^{1}$ Department of Chemistry, University College London, 20 Gordon Street, London, WC1H 0AJ, UK
}

Received ZZZ, revised ZZZ, accepted ZZZ

Published online ZZZ (Dates will be provided by the publisher.)

Keywords Please provide about four verbal keywords for your manuscript.

*Corresponding author: e-mail c.blackman@ucl.ac.uk, Phone: +44 207679 4703, Fax: +44 2076797463

Co-deposition of $\mathrm{Ce}(\mathrm{dbm})_{4}$ and $\mathrm{NH}_{4} \mathrm{AuCl}_{4}$ precursors in acetone at $500^{\circ} \mathrm{C}$ via $\mathrm{AACVD}$ results in deposition of crystalline $\mathrm{CeO}_{2}$ thin films containing/decorated with metallic gold. These particles are estimated to be $\sim 70 \mathrm{~nm}$ in size via optical methods. Preliminary testing of catalytic activity showed the materials were surprisingly catalytically active given the very small amounts of gold present and the large estimated particle size, although the presence of smaller catalytically active particles could not be discounted.

1 Introduction The catalytic activity of gold nanoparticles (NP) increases when supported on oxide thin films, for example $\mathrm{TiO}_{2}$ and $\mathrm{Al}_{2} \mathrm{O}_{3}$, , with the support playing a critical part in the activity. ${ }^{2}$ Cerium oxide $\left(\mathrm{CeO}_{2}\right)$ has been found to increase the catalytic activity of supported gold NP in CO oxidation by two orders of magnitude in comparison to $\mathrm{TiO}_{2}$ or $\mathrm{Fe}_{2} \mathrm{O}_{3}$ supports due to improved dispersion of gold, and the use of an $\mathrm{Au} / \mathrm{CeO}_{2}$ catalyst in the water-gas shift reaction has been shown to be more active than the current commercial catalysts. ${ }^{3}$

Vapour synthesis of gold nanoparticles (NP), e.g. via chemical vapour deposition (CVD), offers advantages over wet-chemical techniques; it circumvents several steps associated with solution methods such as washing, drying, calcination and reduction, and can avoid changes in metal dispersion that can occur during high temperature calcination or reduction steps. ${ }^{4}$

For deposition of $\mathrm{CeO}_{2}$ the typically low volatility of cerium CVD precursors has led to investigation of a widerange of fluorinated $\beta$-diketonates in MOCVD,${ }^{5-9}$ although these tend to lead to fluorine incorporation. ${ }^{10}$ An alterna-

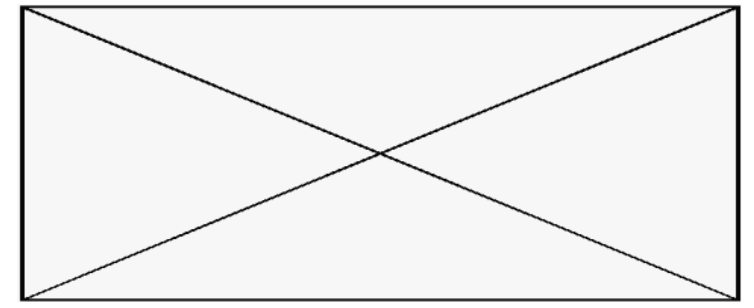

This is the caption of the optional abstract figure. If there is no figure here, the abstract text should be divided into both columns. tive strategy for overcoming low volatility is to introduce the precursor as a solution droplet, and this has been utilized for use of cerium nitrate in electrospray CVD,${ }^{11}$ and for use of $\mathrm{Ce}(\mathrm{thd})_{4}$ (thd = 2,2,6,6-tetramethyl-3,5heptanedionato) in aerosol-assisted CVD. ${ }^{12-14}$

Through extensive experience in the use of AACVD for co-depositing metal NP supported on metal oxides, ${ }^{15,16}$ we have previously observed that use of $\mathrm{HAuCl}_{4}$ or $\mathrm{H}_{2} \mathrm{PtCl}_{6}$ as metal precursors, which in terms of decomposition characteristics are excellent, can be incompatible in solution with metal alkoxide and $\beta$-diketonates when used in a convenient one-pot system containing both precursors. Strategies to alleviate this involve use of more robust metal oxide precursors, for instance the use of $\mathrm{Bi}(\mathrm{dbm})_{3}(\mathrm{dbm}=$ dibenzylmethanato) instead of $\mathrm{Bi}(\text { thd })_{3},{ }^{17}$ or less acidic metal precursors such as metal phosphine cluster complexes ${ }^{18}$ or $\mathrm{NH}_{4} \mathrm{AuCl}_{4} \cdot{ }^{19}$ In this paper we describe the use of $\mathrm{Ce}(\mathrm{dbm})_{4}$ and $\mathrm{NH}_{4} \mathrm{AuCl}_{4}$ precursors in a one-pot AACVD strategy for co-deposition of gold NP-modified $\mathrm{CeO}_{2}$, and report on its catalytic activity for a test oxidation reaction of benzyl alcohol to benzaldehyde. 


\section{Results and Discussion}

2.1 Experimental $\mathrm{Ce}(\mathrm{dbm})_{4}$ was synthesised by adaption of the method for synthesis of $\mathrm{Ce}($ thd $){ }_{4},{ }^{5} \mathrm{H} \mathrm{NMR}$ $\delta / \mathrm{ppm}\left(\mathrm{CDCl}_{3}, 300 \mathrm{MHz}\right): 6.70(\mathrm{~s}, 1 \mathrm{H},(\mathrm{CH})), 7.4(\mathrm{~m}, 9 \mathrm{H}$, $\mathrm{C}_{6} \mathrm{H}_{5^{-}}$plus $\mathrm{CDCL}_{3}$ peak), $8.0\left(\mathrm{~d}, 4 \mathrm{H} \mathrm{C}_{6} \mathrm{H}_{5^{-}}\right)\left({ }^{1} \mathrm{H} \mathrm{NMR}\right.$ dibenzoylmethane $\delta / \mathrm{ppm}\left(\mathrm{CDCl}_{3}, 300 \mathrm{MHz}\right): 6.9(\mathrm{~s}, 1 \mathrm{H})$, $7.5(\mathrm{~m}, 6 \mathrm{H}), 8.0(\mathrm{~m}, 4 \mathrm{H}), 16.9(\mathrm{~s}, 1 \mathrm{H})$, indicating the loss of the $\mathrm{H}$ from the alcohol group after coordination). FT-IR $\mathrm{cm}^{-1}: 1588,1512,1473,1374,1285,1221,1063,1022$, 938, 784, 747, 712, 682, 603, 509, 429 (FT-IR cm ${ }^{-1}$ dibenzoylmethane: 11462, 1308, 1227, 998, 752, 704, 678, 607, 493).

The general AACVD method was as follows: $50 \mathrm{mg}$ $\mathrm{Ce}(\mathrm{dbm})_{4}$ was dissolved in $20 \mathrm{~cm}^{3}$ acetone (and $1 \mathrm{mg}$ $\mathrm{NH}_{4} \mathrm{AuCl}_{4}$ added for gold modified samples), a piezoelectric ultrasonic atomizer (Johnson Mathey Liquifog, 1.6 $\mathrm{MHz}$ ) was used to generate an aerosol from the precursor mixture, which was then carried to the heated substrate $\left(500^{\circ} \mathrm{C}\right)$ by an $\mathrm{N}_{2}$ gas flow $\left(200 \mathrm{~cm}^{3} / \mathrm{min}\right)$. The substrates used were plain glass microscope slides.

Thermal Gravimetric analysis (TGA) was carried out using a NETZSCH STA-449C Jupiter balance under helium flow. X-ray diffraction measurements were completed using a Bruker D8 X-ray diffractometer with $\mathrm{CuK}_{\alpha} 1$ and $\mathrm{CuK}_{\alpha} 2$ radiation of wavelengths $0.154056 \mathrm{~nm}$ and $0.154439 \mathrm{~nm}$ respectively, emitted with an intensity ratio of $2: 1$. A voltage of $40 \mathrm{kV}$ and current of $40 \mathrm{~mA}$ were used. The diffraction pattern was recorded over the range $2 \theta=$ $10-60^{\circ}$. Scanning Electron Microscopy (SEM) was performed using a JEOL JSM-6301F Field Emission Scanning Electron Microscope at an accelerating voltage of $5 \mathrm{keV}$ and Energy Dispersive Analysis by X-Rays (EDAX) was performed using an attached Oxford Instruments INCA Energy EDAX system. X-ray photoelectron spectroscopy (XPS) was carried out using a Thermo K-Alpha spectrometer in constant analyser energy mode and monochromated $\mathrm{Al} \mathrm{K} \alpha$ radiation. Survey scans were collected over the $0-1400 \mathrm{eV}$ binding energy range with $1 \mathrm{eV}$ resolution and a pass energy of $200 \mathrm{eV}$. Higher resolution scans $(0.1$ $\mathrm{eV}$ ) were also collected at a pass energy of $50 \mathrm{eV}$. Data was processed using CasaXPS. Raman spectra were collected using a Renishaw ramascope and UV/Visible/Near IR spectra were taken using a Perkin Elmer Fourier transform Lambda $950 \mathrm{UV} / \mathrm{V}$ is spectrometer over a wavelength range of $300 \mathrm{~nm}$ to $2500 \mathrm{~nm}$ in the transmission mode.

Catalytic testing was carried out using a Multimax Multiple Automatic Lab described previously, ${ }^{20}$ by immersing films in a solution of $4.5 \mathrm{~cm}^{3}$ benzyl alcohol, 11.4 $\mathrm{cm}^{3}$ tetra-butyl hydrogen peroxide (TBHP) and $10 \mathrm{~cm}^{3}$ decane, and stirred at $94^{\circ} \mathrm{C}$ for 4 hours. Samples were collected for analysis at $0,15,30,45,60,120,180$ and 240 minutes. The samples were analysed using a PerkinElmer Clarus 500 Gas Chromatograph with a flame ionization detector to investigate the conversion of benzyl alcohol and the selectivity to the desired product, benzaldehyde.
2.2 Results and Discussion TGA data for $\mathrm{Ce}(\mathrm{dbm})_{4}$ (Figure 1) showed the onset of first mass loss at $\sim 200^{\circ} \mathrm{C}$, coincident with an endotherm in the DSC. This weight loss is attributed to volatilization of the precursor slightly lower than the value found previously for $\mathrm{Ce}(\text { thd })_{4}$ of $250^{\circ} \mathrm{C} .{ }^{21}$ Accelerated weight loss is observed at $\sim 400^{\circ} \mathrm{C}$, coinciding with an exotherm in the DSC and this is attributed to initial decomposition of the precursor, which continues across three distinct steps until $550^{\circ} \mathrm{C}$. Assuming no decomposition prior to $400^{\circ} \mathrm{C}$, the total $\%$ weight loss during decomposition is therefore approximately $50 \%$ whereas the mass loss required for complete conversion of $\mathrm{Ce}(\mathrm{dbm})_{4}$ to $\mathrm{CeO}_{2}$ is $83 \%$, indicating incomplete decomposition (carbon contamination) may be expected during CVD. $\mathrm{NH}_{4} \mathrm{AuCl}_{4}$ decomposes in a single principle step (Figure 1) losing $43 \%$ of its mass by $300^{\circ} \mathrm{C}$, although an initial loss of mass is observed from $50^{\circ} \mathrm{C}$ attributed to loss of water of crystallisation. The mass loss required for complete conversion to pure gold is $55 \%$, indicating residual chloride contamination is possible. In contrast $\mathrm{HAuCl}_{4}$ exhibits two main stages of weight loss after loss of water of crystallization up to $135^{\circ} \mathrm{C}$, with the first step up to $220^{\circ} \mathrm{C}$ corresponding to the loss of $\mathrm{HCl}$ and $\mathrm{Cl}_{2}$ and the second step up to $294^{\circ} \mathrm{C}$ attributed to the disproportionation of $\mathrm{AuCl}$ producing $\mathrm{Au}$ and $\mathrm{Cl}_{2}$.

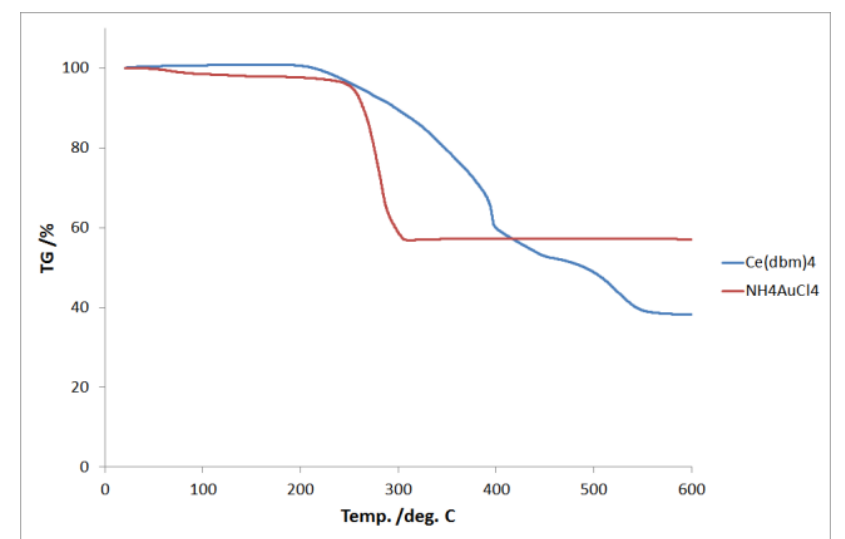

Figure 1 TGA data for $\mathrm{Ce}(\mathrm{dbm})_{4}$ (blue line) and $\mathrm{NH}_{4} \mathrm{AuCl}_{4}$ (red line).

Deposition using $\mathrm{Ce}(\mathrm{dbm})_{4}$ alone produced pale cream opaque films. XRD analysis showed good agreement for cerium oxide (Fm-3m space group, $\mathrm{a}=\mathrm{b}=\mathrm{c}=5.507$ (3) $\AA$; ICDD card no. 01-081-0792 $\mathrm{a}=\mathrm{b}=\mathrm{c}=5.4124 \AA$ ) (Figure 2). ${ }^{22}$ 


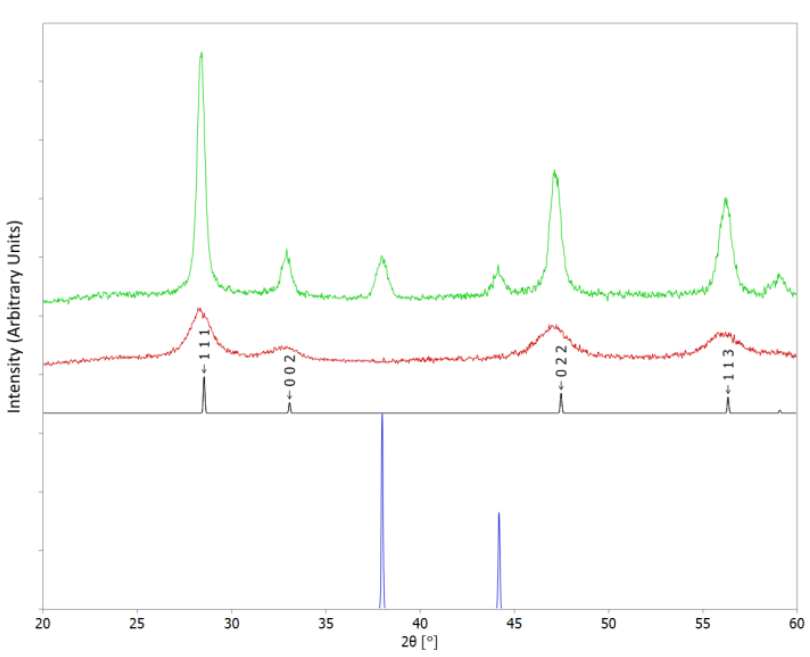

Figure 2 XRD patterns of films deposited at $500^{\circ} \mathrm{C}$ from $\mathrm{Ce}(\mathrm{dbm})_{4}$ only (red line) or $\mathrm{Ce}(\mathrm{dbm})_{4} / \mathrm{NH}_{4} \mathrm{AuCl}_{4}$ (green line). Literature patterns for $\mathrm{CeO}_{2}$ (black) and $\mathrm{Au}$ (blue) are also shown.

Raman spectroscopy shows a peak centred at $456 \mathrm{~cm}^{-1}$ (Figure 3), in accordance with the literature value for $\mathrm{CeO}_{2}$ $\left(465 \mathrm{~cm}^{-1}\right) .{ }^{23}$

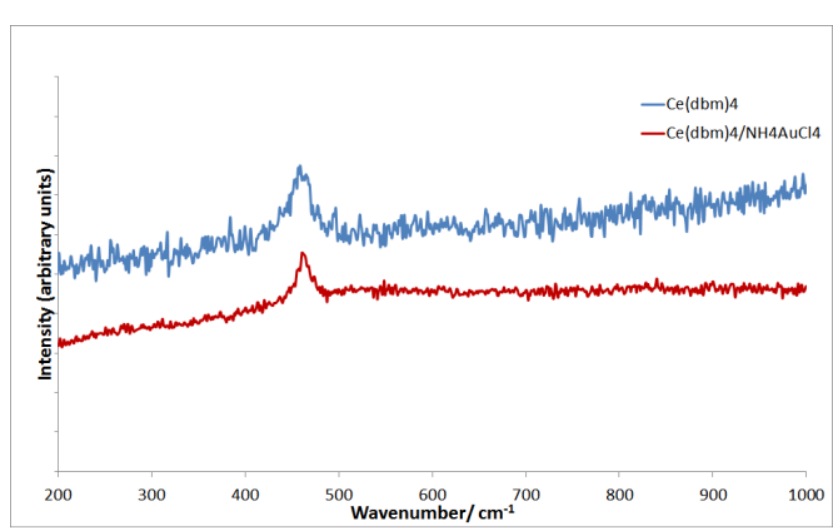

Figure 3 Raman spectra of films deposited at $500^{\circ} \mathrm{C}$ from $\mathrm{Ce}(\mathrm{dbm})_{4}$ only (blue line) or $\mathrm{Ce}(\mathrm{dbm})_{4} / \mathrm{NH}_{4} \mathrm{AuCl}_{4}$ (red line)

UV-vis spectra of a film deposited at $500^{\circ} \mathrm{C}$ is shown in Figure 4a, compared to a blank glass substrate (Figure $4 \mathrm{c}$; peaks at $\sim 850 \mathrm{~nm}$ are due to a detector change on the instrument). The band-gap (Eg) of a semiconductor can be inferred from its UV-Vis spectra using the following equation:

$$
(\alpha \mathrm{hv}) \mathrm{n}=\mathrm{A}(\mathrm{hv}-\mathrm{Eg})
$$

Where $\alpha$ corresponds to the absorption coefficient, hv is the photon energy, and $\mathrm{n}$ represents the index which depends on the electronic transition of the semiconductor. ${ }^{24}$ Estimation of the bandgap from the band edge for the
$\mathrm{CeO}_{2}$ film indicates a value of $\sim 3.1 \mathrm{eV}$, in good agreement with the literature value of $3.15 \mathrm{eV} .^{25}$

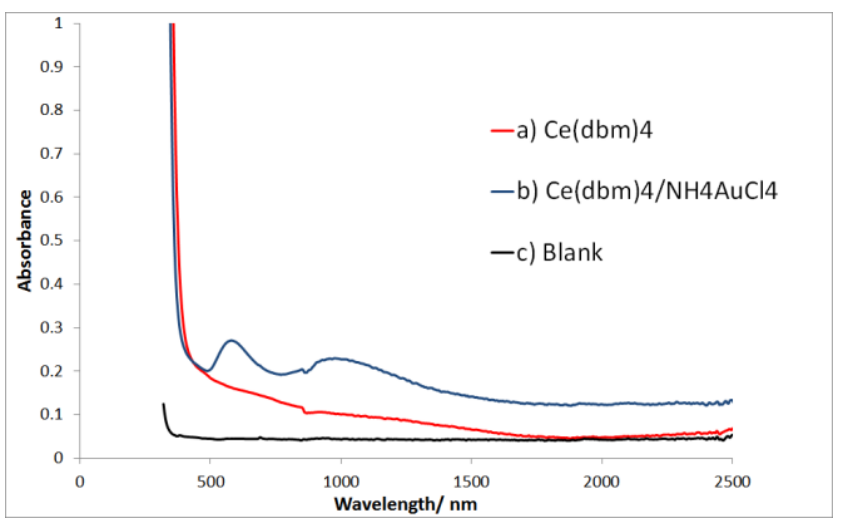

Figure $4 \mathrm{UV}$-vis spectra of films deposited at $500^{\circ} \mathrm{C}$ from a) $\mathrm{Ce}(\mathrm{dbm})_{4}$ only (red line), b) $\mathrm{Ce}(\mathrm{dbm})_{4} / \mathrm{NH}_{4} \mathrm{AuCl}_{4}$ (blue line) compared to, c) blank glass substrate (black line)

Bêche et al. ${ }^{26}$ carried out an XPS study of cerium oxide and mixed cerium oxides assigning six peaks, corresponding to pairs of spin-orbit doublets (labelled v and $\mathrm{u}$ ), in the Ce $3 \mathrm{~d}_{3 / 2,5 / 2}$ spectrum. Analysis of a film deposited at $500^{\circ} \mathrm{C}$ (Figure 5) found peaks at 916.8 (u'"'), 898.1 (v'"'), 906.4 (u'), 887.8 (v'), 901.2 (u) and 882.6 (v). The u'"' (916.9), v"' (898.3) and the u (901.3), v (882.7) peaks are in very good agreement with the literature values (shown in brackets) although the u" (907.3), v" (888.5) peaks are noticeably different. The satellite u" "peak is indicative of the presence of $\mathrm{Ce}(\mathrm{IV})$.

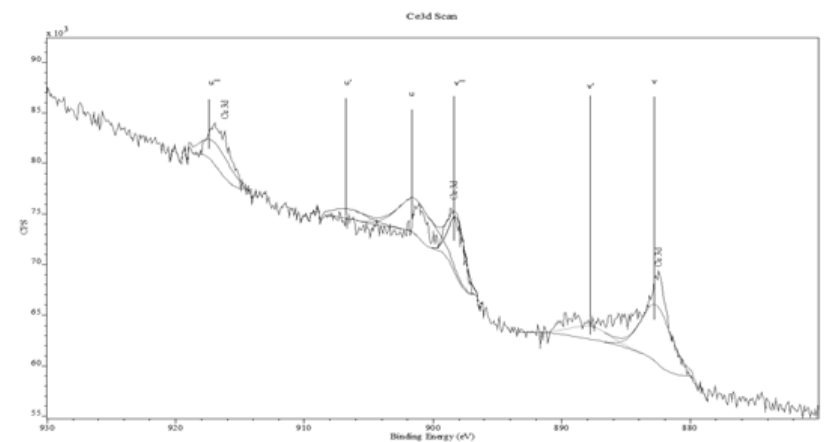

Figure 5 XPS spectrum of film deposited at $500^{\circ} \mathrm{C}$ from $\mathrm{Ce}(\mathrm{dbm})_{4}$ only

SEM analysis showed the films were comprised of separated grains comprised of agglomerates of smaller crystallites (Figure 6A) 


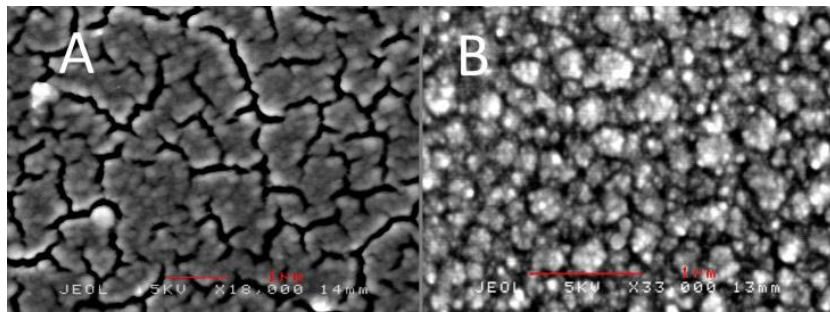

Figure 6 SEM image of film deposited at $500^{\circ} \mathrm{C}$ from $\mathrm{Ce}(\mathrm{dbm})_{4}$ only (A) or $\mathrm{Ce}(\mathrm{dbm})_{4} / \mathrm{NH}_{4} \mathrm{AuCl}_{4}$ (B) (in both images scale bar in red depicts $1 \mu \mathrm{m}$ )

Addition of $\mathrm{NH}_{4} \mathrm{AuCl}_{4}$ into the reaction mixture caused deposition of blue/black coloured films. Annealing in air at $500^{\circ} \mathrm{C}$ resulted in films with a deep blue colouration. XRD analysis showed evidence of crystalline $\mathrm{CeO}_{2}$ (Fm-3m space group , $\mathrm{a}=\mathrm{b}=\mathrm{c}=5.492(2) \AA)$ as previously and also the presence of metallic gold (Fm-3m space group, $a=b$ $=\mathrm{c}=4.070(1) \AA$; ICDD card no. 00-04-0784 $\mathrm{a}=\mathrm{b}=\mathrm{c}=$ $4.0786 \AA$ ) (Figure 2). Raman spectroscopy was indicative of the presence of $\mathrm{CeO}_{2}$ (Figure 3). EDX gave a $\mathrm{Ce} / \mathrm{Au}$ weight $\%$ ratio of 10:1, very close to the weight ratio of the metals in the precursor solution. SEM (Figure 6B) showed a change in morphology compared to films deposited in the absence of $\mathrm{NH}_{4} \mathrm{AuCl}_{4}$, appearing rougher with more defined island-morphology. XPS analysis agreed closely with literature values for $\mathrm{CeO}_{2}$ with peaks at 917.0 (u' ''), 898.4 (v'"'), 907.0 (u'), 888.4 (v'), 901.3 (u) and 882.7 (v) eV. Peaks were also observed in the $\mathrm{Au} 4 \mathrm{f}$ region with binding energies 83.7 and $87.4 \mathrm{eV}$, in good agreement with the literature values of $84.0,87.9 \mathrm{eV}$ for metallic gold, ${ }^{27}$ demonstrating the presence of gold at the surface of the codeposited films. Comparison with EDX data showed no evidence for surface segregation of Au with almost identical $\mathrm{Ce} / \mathrm{Au}$ ratios found via both techniques.

UV-vis spectra (Figure 4) displayed a broad absorbance between 500 and $650 \mathrm{~nm}$, attributed to the surface plasmon resonance of the gold particles, with the peak centre at $\sim 580 \mathrm{~nm}$. Estimation of gold particle size from the peak absorbance of the plasmon observed using UV-vis spectroscopy (Figure 4), using multipole scattering theory as described by Haiss et $a l^{28}$ and assuming the gold particles were spherical and uncoated and the refractive index of the medium in contact with the particles was dominated by $\mathrm{CeO}_{2}(\sim 2.2 \text { at } 550 \mathrm{~nm})^{29}$, gave a value of $70 \mathrm{~nm}$. This is far in excess of the desired size for catalytic gold nanoparticles, for instance Haider et $\mathrm{al}^{30}$ investigated the effect gold nanoparticle size had on the catalytic activity of $\mathrm{Au} / \mathrm{TiO}_{2}$ and $\mathrm{Au} / \mathrm{CeO}_{2}$ where the gold particles ranged in size from 1.3-11.3 $\mathrm{nm}$ and it was found that the highest catalytic activity emerged for an average particle size of $6.9 \mathrm{~nm}$. However the gold loading in these experiments was high (10 wt.\% Au compared to Ce in precursors) due to practical limitations in preparing solutions at lower concentrations and this is the likely cause of the large particle size since we have previously observed much smaller par- ticles when using $\mathrm{HAuCl}_{4}$ or $\mathrm{H}_{2} \mathrm{PtCl}_{6} \cdot{ }^{31} \mathrm{We}$ also note that our analysis does not preclude the presence of undetectable gold particles within the catalytically active range identified by Haider, but difficulty with sample preparation precluded identifying these using electron microscopy.

Films deposited from $\mathrm{Ce}(\mathrm{dbm})_{4} \quad\left(\mathrm{CeO}_{2}\right)$ and $\mathrm{Ce}(\mathrm{dbm})_{4} / \mathrm{NH}_{4} \mathrm{AuCl}_{4}\left(\mathrm{Au} / \mathrm{CeO}_{2}\right)$ were tested for catalytic activity during oxidation of benzyl alcohol (Table 1). The selective catalytic oxidation of hydrocarbons to their respective aldehydes is a major challenge for industry and reactions are frequently performed at very low conversion rates in order to avoid the formation of carboxylic acids. ${ }^{32}$ Oxidation of benzyl alcohol to benzaldehyde is a useful test reaction as it is easily over-oxidised to benzoic acid and therefore provides a direct measure of the selectivity of the catalyst. It is clear that both the plain glass substrate and $\mathrm{CeO}_{2}$ thin film had no measurable activity during the period of test. The $\mathrm{Au} / \mathrm{CeO}_{2}$ film tested showed measurable conversion and turnover number (TON), with very good selectivity towards benzaldehyde. However it should be noted that the amount of reagents used in this reaction were designed to be used with 200-250 mg gold as catalyst but the amount of active catalyst present in our films being significantly lower than this hence the low total conversion (average amount of material in $2 \mathrm{~cm}^{2}$ thin film, the maximum size that could fit in reactor, is $2 \mathrm{mg}$ and then by using EDX the amount of gold in the sample can be estimated). The TON value is greater than a sample of gold nanoparticles supported on $\mathrm{SiO}_{2}$ prepared via solution-phase impregnation/calcination (TON 580), although lower than gold nanoparticles supported on nanostructured tungsten oxide $(20000$, although the surface area here is expected to be considerably lower). ${ }^{18}$

Table 1. Catalytic performance of film deposited from $\mathrm{Ce}(\mathrm{dbm})_{4}$ and $\mathrm{NH}_{4} \mathrm{AuCl}_{4}$ at $500^{\circ} \mathrm{C}$.

\begin{tabular}{lllll}
\hline Sample & $\begin{array}{l}\text { Conversion } \\
\text { to } \\
\text { oxidized } \\
\text { products \% }\end{array}$ & $\begin{array}{l}\text { TON (gold } \\
\text { only) }\end{array}$ & $\begin{array}{l}\text { Selectivity to } \\
\text { benzaldehyde } \\
\%\end{array}$ & $\begin{array}{l}\text { Estimated } \\
\text { Mass Gold } \\
\text { from EDX } \\
/ \mathrm{mg}\end{array}$ \\
\hline $\begin{array}{l}\text { Plain } \\
\text { Glass }\end{array}$ & 0.0 & - & 0.0 & 0.0 \\
$\mathrm{CeO}_{2}$ & 0.0 & - & 0.0 & 0.0 \\
$\mathrm{Au}$ & 8.2 & 3600 & 91.1 & 0.2 \\
$\mathrm{CeO}_{2}$ & & & & \\
\hline
\end{tabular}

3 Conclusions Co-deposition of $\mathrm{Ce}(\mathrm{dbm})_{4}$ and $\mathrm{NH}_{4} \mathrm{AuCl}_{4}$ precursors in acetone at $500^{\circ} \mathrm{C}$ via $\mathrm{AACVD}$ results in deposition of crystalline $\mathrm{CeO}_{2}$ thin films containing/decorated with metallic gold. These particles are estimated to be $\sim 70 \mathrm{~nm}$ in size via optical methods. Prelimi- 
nary testing of catalytic activity showed the materials were surprisingly catalytically active given the very small amounts of gold present and the large estimated particle size (although the presence of smaller particles cannot be discounted). It has been found previously that higher catalytic performance is observed in CVD deposited materials than those produced using solution-phase methods and these results may reflect this. ${ }^{33}$ Future work is aimed at reducing the gold loading, and in particular reducing the gold particle size, and observing the effect on the catalytic activity.

Acknowledgements An acknowledgement may be placed at the end of the article.

\section{References}

[1] M. Comotti, W. Li, B. Spliethoff, F. Schüth, J. Am. Chem. Soc., 128, 917 (2006).

[2] A. Kozlov, A. Kozlova, H. Liu, Y. Iwasawa, Appl Catal. A General, 182, 93 (1999).

[3] S. Senanayake, D. Stacchiola, J. Evans, M. Estrella, L. Barrio, M. Pérez, J. Hrbek, J. Rodriguez, J. Catal., 271, 392 (2010).

[4] A. E. Aksoylu, J. L. Faria, M. F. R. Pereira, J. L. Figuieredo, P. Serp, J. -C. Hierso, R. Feurer, Y. Kihn, P. Kalck, Appl. Catal A: General, 243, 357 (2003).

[5] M. Becht, T. Gerfin, K-H. Dahmen, Chem. Mater., 5, 137 (1993).

[6] I. Baxter, J. Darr, M. Hursthouse, K. Abdul Malik, J. McAleese, D. Michael, P. Mingos, Polyhedron, 17, 1239 (1998).

[7[ K. Pollard, H. Jenkins, R. Puddephatt, Chem. Mater., 12, 701 (2000).

[8] G. Malandrino, R. Lo Nigro, C. Benelli, F. Castelli, I. Fragalà, Chem. Vap. Deposition, 6, 233 (2000).

[9] R. Lo Nigro, G. Malandrino, I. Fragalà, Chem. Mater., 13, 4402 (2001).

[10] J. McAleese, J. Plakatauros, B. Steele, Thin Solid Films, 280, 152 (1996).

[11] M. Wei, K. Choy, J. Crystal Growth, 284, 464 (2005).

[12] K. Frölich, J. Šouc, D. Machajdîk, A. Kobzev, F. Weiss, J. Senateur, K. Dahmen, J. Physique IV, 5, 533 (1995).

[13] C. Xia, T. Ward, R. Schwartz, Chem. Vap. Deposition, 2, 48 (1996).

[14] M. Siadati, T. Ward, J. Martus, P. Atanasova, C. Xia, R. Schwartz, Chem. Vap. Deposition, 3, 311 (1997).

[15] C. Navío, S. Vallejos, T. Stoycheva, E. Llobet, X. Correig, R. Snyders, C. Blackman, P. Umek, X. Ke, G. Van Tendeloo, C. Bittencourt, Mat. Chem. Phys., 134, 809 (2012).

[16] T. Stoycheva, S. Vallejos, J. Calderer, I. Parkin, C. Blackman, X. Correig, Procedia Engineering, 5, 131 (2010).

[17] S. J. A. Moniz, D. Bhachu, C. S. Blackman, A. J. Cross, S. Elouali, D. Pugh, R. Quesada Cabrera, S. Vallejos, Inorganica Chimica Acta, 380, 328 (2012).

[18] A. Molkenova, R. Sarip, S. Sathasivam, P. Umek, S. Vallejos, C. Blackman, G. Hogarth, G. Sankar, Sci. Technol. Adv. Mater., 15, 065004 (2014).

[19] F. Di Maggio, M. Ling, A. Tsang, J. Covington, J. Saffell, C. Blackman, J. Sens. Sens. Syst., 3, 325 (2014).
[20] A. Welch, N. Shiju, I. Watts, G. Sankar, S. Nikitenko, W. Bras, Catal. Lett., 105, 179 (2005).

[21] M. Leskela, R. Sillanpaa, L. Niinisto, M. Tiitta, Acta Chem. Scand., 45, 1006 (1991).

[22] M. Wolcyrz, L. Kepinski, J. Sol. State Chem., 99, 409 (1992).

[23] J. Twu, C. Chuang, K. Chang, C. Yang, K. Chen, Applied Catalysis B: Envir., 12, 309 (1997).

[24] J. Tauc, R. Grigorovici, A. Vancu, physica status solidi (b), 15, 627 (1966).

[25] F. Zhang, Q. Jin, S. Chan, J. Appl. Phys., 95, 4319 (2004).

[26] E. Bêche, P. Charvin, D. Perarnau, S. Abanandes, G. Flamant, Sur. Inter. Anal., 40, 264 (2008).

[27] P. Bera, M. Hedge, Catal. Lett., 79, 75 (2002).

[28] W. Haiss, N. T. K. Thanh, J. Aveyard, D. G. Fernig, Anal. Chem., 79, 4215 (2007).

[29] G. Hass, J. B. Ramsey, R. Thun, J. Optical Soc. Am., 48, 324 (1958).

[30] P. Haider, B. Kimmerle, F. Krumeich, W. Kleist, J. Grunwaldt, A. Baiker, Catal. Lett., 125, 169 (2008).

[31] S. Vallejos, P. Umek, T. Stoycheva, F. Annanouch, E. Llobet, X. Correig, P. De Marco, C. Bittencourt, C. Blackman, Adv. Funct. Mater., 23, 1313 (2013).

[32] K. R. Seddon, A. Stark, Green Chem., 4, 119 (2002).

[33] V. Garcia, Mater. Sci. Eng., 20, 012001 (2011). 